\title{
Banded Sleeve Gastrectomy Using the GaBP Ring - Surgical Technique
}

\author{
Wojciech Konrad Karcz ${ }^{\mathrm{a}}$ Goran Marjanovic ${ }^{\mathrm{a}} \quad$ Jodok Grueneberger $^{\mathrm{a}}$ Tobias Baumann ${ }^{\mathrm{b}}$ \\ Waleed Bukharic ${ }^{c}$ Daniel Krawczykowski ${ }^{\mathrm{d}}$ Simon Kuesters ${ }^{\mathrm{a}}$ \\ ${ }^{a}$ Department of General and Visceral Surgery, \\ ${ }^{\mathrm{b}}$ Department of Radiology, University of Freiburg, Germany \\ ' Department of Surgery, International Medical Center, Jeddah, Saudi Arabia \\ ${ }^{\mathrm{d}}$ Department of Surgery, Hopital Chalons en Champagne, France
}

\section{Keywords}

Laparoscopy · Sleeve gastrectomy .

Banded sleeve gastectomy · GaBP Ring · Restriction

\section{Summary}

Laparoscopic sleeve gastrectomy (LSG) has been described as the first step of a two-step laparoscopic Roux-en-Y gastric bypass (LRYGB) or biliopancreatic diversion with duodenal switch (BPD-DS) in extremely obese patients. It has also been used as an independent bariatric procedure. Recently a banded sleeve gastrectomy using human dermis was published. Gastric sleeve dilatation is one of the unfavorable postoperative courses that may limit weight loss. Our technique of a banded sleeve gastrectomy using the GaBP Ring Autolock ${ }^{\mathrm{TM}}$ System to calibrate the sleeve and prevent distal sleeve dilatation is described in this article.

\section{Introduction}

A substantial part of bariatric operations contain the implantation of a band. The minimally invasive restrictive intervention of a band placed around the upper stomach to create a small proximal pouch has gained worldwide recognition as gastric banding $[1,2]$. The vertical banded gastroplasty (VBG) also was a very popular operation technique for a long time $[3,4]$. Further development lead to the banded gastric bypass by Fobi, the gastroplasty modification, the Mill Magenstraße ( $\mathrm{M}$ and $\mathrm{M}$ ) procedure and in consequence the laparoscopic sleeve gastrectomy (LSG) [5-7]. In the latter operation the stomach is reduced to a narrow tube which dramatically re- duces the volume and decreases the gastric peristaltic 'wave'. Further investigation showed that a significantly better excess weight loss (EWL) can be achieved by using a $32 \mathrm{~F}$ gastric tube for the sleeve resection [8]. The LSG has been described as the first stage of the two-step gastric bypass procedure (laparoscopic Roux-en-Y gastric bypass; LRYGB) or biliopancreatic diversion with duodenal switch (BPD-DS) in morbidly obese patients $[9,10]$. However, it is recently more often used as a sole bariatric operation [7, 11-14]. We developed a hybrid operation between sleeve gastrectomy and VGB named banded sleeve gastrectomy, using the GaBP Ring Autolock ${ }^{\mathrm{TM}}$ System (Baritec, El Dorado Hills, CA, USA). Recently, other authors have published their initial experiences with the banded sleeve gastrectomy using other banding materials $[15,16]$.

The dilatation of the gastric sleeve created in LSG can progress in time and may be a potential source of therapy failure. Placing a silastic ring at the outlet of the pouch to prevent dilatation of the gastric pouch in LRYGB procedure already shows promising results [17]. Studies describing the incidence of gastric tube dilatation and methods to prevent this unfavorable course after LSG are lacking [12]. In our collective at about one fifth of patients who regain weight after sleeve gastrectomy have a sleeve volume $>300 \mathrm{ml}$ when assessed by 3D-CT with gastric volumetry [18]. We propose the sleeve gastrectomy with implantation of a siliastic ring for prevention of lower gastric sleeve dilatation (fig. 1, 2). GaBP Ring Autolock ${ }^{\mathrm{TM}}$ System is made of silicone, has a locking mechanism and is available in various sizes. It is currently pending approval from the FDA but has the CE certification for the European market where it is also used for banded gastric bypass operations. The hypothesis of possible superiority of banded over conventional LSG will be evaluated in a prospective, randomized trial which started this year in our clinic.

\section{KARGER \\ Fax +497614520714 \\ Information@Karger.de}

www.karger.com
(C) 2011 S. Karger GmbH, Freiburg

$1662-4025 / 11 / 0041-0077 \$ 38.00 / 0$

Accessible online at:

www.karger.com/ofa
Wojciech Konrad Karcz, MD

Department of General and Visceral Surgery

University of Freiburg

Hugstetter Straße 55, 79106 Freiburg, Germany

Tel. + 49761270 28-06, Fax -04

konrad.karcz@uniklinik-freiburg.de 
Fig. 1. The laparoscopic banded sleeve gastrectomy (LBSG).

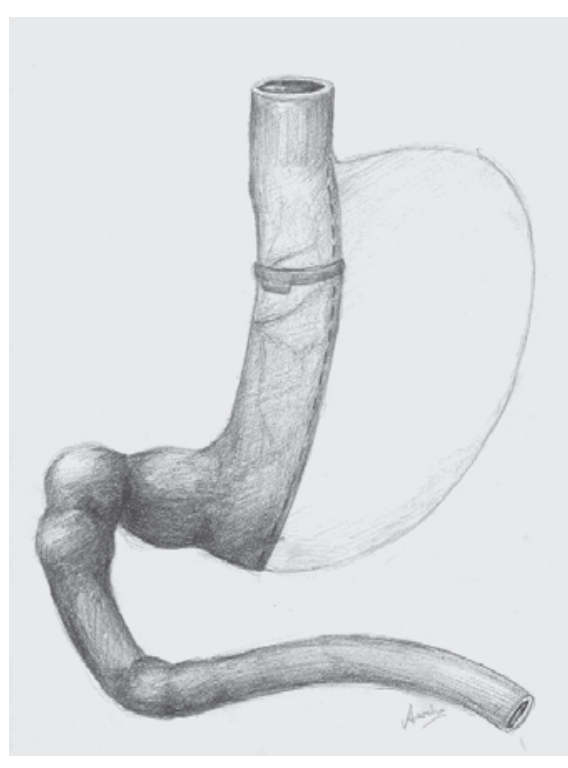

\section{Operative Technique for Laparoscopic Banded Sleeve Gastrectomy}

We perform the operation as a two-surgeon procedure with the patient in the lithotomic position and the operating table in a 30 degree reverse Trendelenburg tilt. The surgeon stands between the patient's legs with one assistant on the left side of the patient. After penetrating into the abdominal cavity with a $12 \mathrm{~mm}$ single-use separator trocar (Applied Medical, Rancho Santa Margerita, CA, USA) through the Musculus rectus abdominis in the left lateral quadrant, insufflation of carbon dioxide is commenced with a set point at $16 \mathrm{~mm} \mathrm{Hg}$ (Termoflator Set, Storz, Tuttlingen, Germany). When a pressure of $14 \mathrm{~mm} \mathrm{Hg}$ is reached, two $12 \mathrm{~mm}$ single-use separator trocars are inserted (Applied Medical) in the right paramedian epigastrium and the lateral border of the left M. rectus abdominis. A liver retractor is introduced without an extra port in the epigastrium. A 30 degree high definition television (HDTV) optic is used (Storz, Tuttlingen, Germany). The epigastric region is exposed by lifting the left lobe of the liver with a liver retractor and by pulling down the fundus of the stomach with alligator forceps.

The dissection begins on the greater curvature approximately $5-6 \mathrm{~cm}$ from the pylorus. The large curvature of the stomach is separated from the omentum majus using the LigaSure Advanced (Covidien, Dublin, Ireland). Once the bursa omentalis is entered, the dissection is continued in a cephalic direction until the upper pole of the spleen is reached. At the level of the spleen, the short gastric vessels are carefully coagulated. The dissection progresses until the left crus of the diaphragm is well visualized. A $32 \mathrm{~F}$ gastric tube is then introduced per os by the anesthetist and advanced into the stomach. Two $45 \mathrm{~mm}$ blue linear staplers

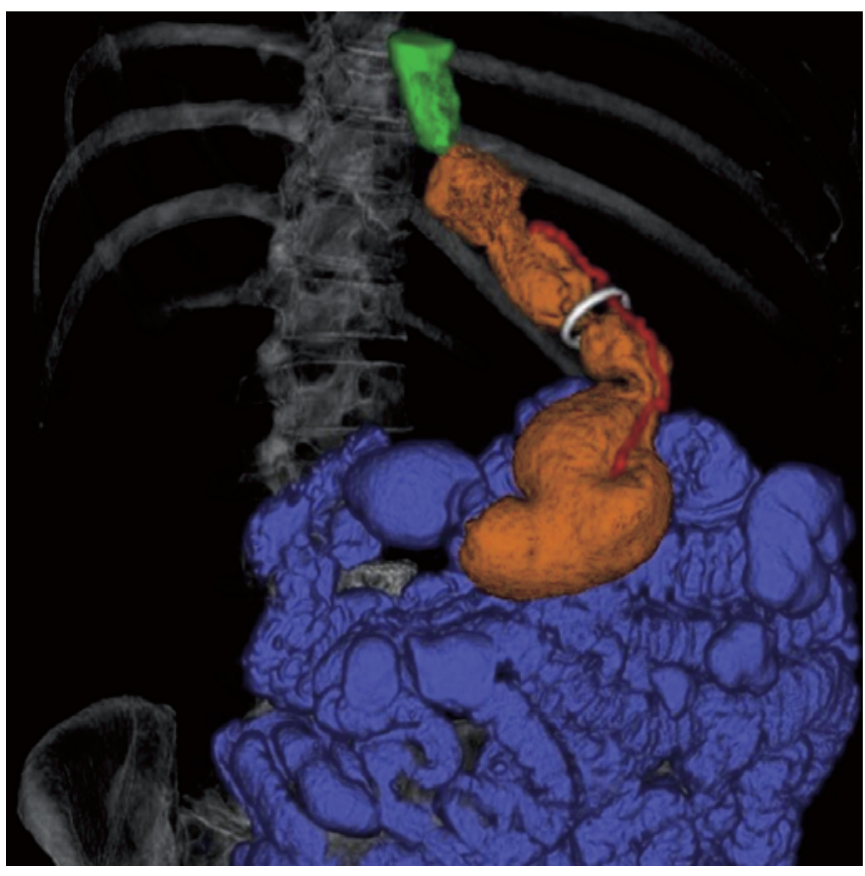

Fig. 2. $3 \mathrm{D}$ volume rendering image in right-anterior-cranial-oblique projection of a 50-year-old female case. Different color masks are employed to allow separate depiction of the stomach (orange), esophagus (green), and intestine (cyan). A semitranslucent mask of the ribcage and spine is provided for better anatomical orientation. The GaBP Ring ${ }^{\mathrm{TM}}$ (white) was placed around the gastric sleeve approximately $6 \mathrm{~cm}$ distal from the His angle.

(GIA Roticulators; Covidien, Dublin, Ireland) are used starting about $6 \mathrm{~cm}$ from the pylorus. The tip of the stapler is oriented towards the left of the visible endings of the lesser curvature vessels. Then, 4-5 $60 \mathrm{~mm}$ staplers (Covidien) are used to resect the stomach up to the angle of His. A gastric tube ('sleeve') less than $100 \mathrm{ml}$ in volume remains. A $10 \mathrm{~mm}$ retrieval system is used to remove the resected stomach specimen (Monarch Retrieval System; Applied Medical,). The stapler line is sutured with a sero-serosal vicryl suture (3-0) for bleeding prevention. A canal is created around the stomach with a dissector and LigaSure $6 \mathrm{~cm}$ distal to the His angle. The GaBP Ring $6.5 \mathrm{~cm}$ is introduced into the peritoneal cavity through the $12 \mathrm{~mm}$ trocar. The ring is placed circumferentially around the gastric tube through the previously created canal. The tapered tip of the ring introducer is thread through this canal and grasped with a grasping clamp, and the ring is pulled through. The female catch portion of the ring is grasped and pulled to separate the introducer from the ring. Male and female endings of the ring are then grasped, approximated, and the ring is locked. The area is carefully inspected for bleeding or sliding of the ring. Diluted half-strength methylene blue dye $(150 \mathrm{ml})$ is used to test for leaks. The fascial defect after the stomach extirpation is closed by single suture and the skin wounds by stapling. 


\section{Discussion}

Sleeve gastrectomy is the first (restrictive) step of the restrictive and malabsorptive BPD-DS. Hess and Hess [19] performed the first BPD-DS in March 1988 (in a woman with BMI of $60 \mathrm{~kg} / \mathrm{m}^{2}$ who had BMI of $29 \mathrm{~kg} / \mathrm{m}^{2} 17$ years later [9]), and Marceau et al. published their first report in 1993 [20] and long-term results in 1999 [21]. In June 1999, the working group of Gagner performed the first fully laparoscopic BPDDS [22, 23]. Sleeve gastrectomy has also been used as a first step prior to gastric bypass operations. Regan et al. [24] reported on LSG as a first-step procedure followed by gastric bypass in excessively obese patients. In that series, 7 patients achieved a primary mean EWL of $33 \%$ after a mean period of 11 months, and the mean BMI was reduced from 63 to $50 \mathrm{~kg} /$ $\mathrm{m}^{2}$. In a second step, the sleeve gastrectomy was converted to an LRYGB. This approach in the super-obese was also reported by Nguyen et al. [25]. When comparing LSG and intragastric balloon as a first-step procedure for super-obesity, Milone et al. [26] found sleeve gastrectomy to be more effective, with an EWL of $35 \%$ after 6 months.

In a study by Nocca et al. [14], only at about one third of the LSG patients needed the BPD-DS as a second step 3 years after the primary operation. Consequently, LSG is also used as an isolated independent procedure, but long-term results do rarely exist. The LSG procedure eliminates the portion of stomach which produces ghrelin hormone, thus diminishing hunger. Dumping syndrome is not seen after LSG as the pylorus and the intestinal continuity is preserved. This technique can be an appealing option for patients with anemia and inflammatory bowel disease requiring anti-inflammatory medication in whom the intestinal bypass of the duodenal switch is too risky. The LSG is also an adequate option for patients who require therapy with oral anticoagulants since intestinal resorption is not compromised. Efficiency of weight loss after sleeve gastrectomy alone was reported in several studies on super-obese patients. A recent report of LSG in 60 morbidly obese Koreans found $83 \%$ EWL at 12 months, with only 1 patient requiring a second operation (BPD-DS) [27]. In a prospective, randomized study comparing LSG to LAGB, LSG lead to $66 \%$ EWL at 3-year follow-up [28].

In a series reported by Almogy et al. [13], sleeve gastrectomy was performed via laparotomy in 21 high-risk superobese patients not eligible for BPD-DS due to high perioperative risk, hemodynamic instability or liver cirrhosis discovered on operation. These patients achieved a mean EWL of $45 \%$ at 12 months postoperatively [13].

Langer et al. [12] reported that a mean EWL of $46 \%$ was achieved only 6 months after LSG, while the mean BMI was reduced from 48 to $36 \mathrm{~kg} / \mathrm{m}^{2}$. In this study, weight loss after LSG was not only shown in super-obese patients, but also in a group with a BMI lower than $50 \mathrm{~kg} / \mathrm{m}^{2}$. For patients with a lower BMI $\left(35-43 \mathrm{~kg} / \mathrm{m}^{2}\right)$, early results of the single-stage procedure appear promising, but so far follow-up is too short. Iso- lated LSG may become the primary recommendation for these patients instead of LAGB because no adjustments are needed, an excess stomach volume is removed, and additionally the local hormonal changes lead to quicker satiety and optimize pancreas function. In recent study, Himpens et al. [29] describe weight loss up to 6 years after sleeve gastrectomy. Their collective includes patients with a BMI ranging from 31 up to 57 $\mathrm{kg} / \mathrm{m}^{2}$. They found a good EWL of $72.8 \%$ after 3 years, but it dropped to $57.3 \%$ after 6 years. Little is known about possible long-term complications of sleeve gastrectomy, but weight regain possibly is caused by dilation of the sleeve.

In a study by Langer et al. [12], dilatation was diagnosed by upper gastrointestinal contrast studies in patients after LSG with a follow-up of more than 12 months. Weight regain was not a mandatory consequence of gastric dilatation as the only patient presenting with gastric dilatation achieved an EWL of $59 \%$ at 12 months and maintained a stable weight. In the short-term follow-up of that series, gastric dilatation may not have been a limiting factor for the conventional sleeve gastrectomy as a single bariatric operation. Nonetheless, patients ought to be informed about possible dilatation and that a second-step operation may be necessary in the case of inadequate weight loss or weight gain. In our collective, a sleeve dilation is seen in one fifth of patients with poor weight loss after LSG. Gastric dilatation has also been reported after sleeve gastrectomy as part of BPD-DS $[18,30]$. In these patients a regain of weight was seen and could be successfully treated by a re-sleeve gastrectomy. The above mentioned issues lead to the conclusion that adding a silastic band to sleeve gastrectomy might increase the success rate by preventing gastric tube dilatation. A ring diameter of $6.5 \mathrm{~cm}$ was chosen on the basis of quality of life and quality of eating studies performed in relation to the size of the ring in gastric bypass $[31,32]$. However, it must be mentioned that, compared to conventional LSG, additional potential complications may occur following laparoscopic banded sleeve gastrectomy (LBSG), e.g. silicone band migration, dislocation or infection and dysphagia-related symptoms. All of these disadvantages have been observed in VGB and Fobi-banded gastric bypass, but in low rates $[33,34]$. Postoperative leakage after sleeve gastrectomy are mostly located at the gastroesophageal junction and the prepyloric region [35]. Most leaks can be managed with drainage and intraluminal stenting [36-38]. Another new and promising option is the endoluminal vacuum therapy of upper intestinal tract insuffiencies [39]. In case of a leak after banded sleeve gastrectomy, however, percutaneous drainage is not adequate if the ring is directly affected. In such cases we propose the laparoscopic lavage and drainage with removal of the GaPB-Ring, followed by intraluminal stenting. A contamination of the ring with subsequent infection must be avoided. In such cases it is also possible to place the ring again after complete recovery. Sleeve gastrectomy seems to be a well tolerated procedure in patients with a BMI greater than $50 \mathrm{~kg} / \mathrm{m}^{2}$. Since our patients had contraindications 
against BPD-DS and LRYGB, we decided to perform LBSG. So, what is the role of LBSG? We suggest an indication based on the following selection criteria. LBSG should be considered in patients:

- in whom there are clear contraindications against gastric bypass or BPD, or

- on medication that depends on exact and reliable intestinal resorption.

There is increasing evidence that a LSG is a well tolerated operation, but the overall re-operation rate (including secondstep operations) is close to $50 \%$ after 5 years due to regaining of weight [28]. LBSG is relatively easy to perform as well. It might be superior to conventional LSG because it could prevents distal sleeve dilatation, an important, potentially outcome-limiting complication. This hypothesis is currently being tested in a prospective randomized trial that we initiated this year.

\section{Disclosure Statement}

The authors declare no conflicts of interest.

\section{References}

1 Favretti F, Segato G, De MF, De LM, Lise M, Cadiere GB, Himpens J, Capelluto E, Gaudissart Q: An adjustable silicone gastric band for laparoscopic treatment of morbid obesity - technique and results. Surg Technol Int 2002;10:109-114.

2 Buchwald H, Ikramuddin S: Laparoscopic adjustable gastric banding in bariatric surgery: an overview of the LAP-BAND. Introduction. Am J Surg 2002;184:1S-3S

3 Buchwald H, Williams SE: Bariatric surgery worldwide 2003. Obes Surg 2004;14:1157-1164.

4 Buchwald H, Avidor Y, Braunwald E, Jensen MD, Pories W, Fahrbach K, Schoelles K: Bariatric surgery: a systematic review and meta-analysis. JAMA 2004;292:1724-1737.

5 Fobi MA, Lee H: The surgical technique of the FobiPouch operation for obesity (the transected silastic vertical gastric bypass). Obes Surg 1998:8:283-288.

6 Johnston D, Dachtler J, Sue-Ling HM, King RF, Martin G: The Magenstraße and Mill operation for morbid obesity. Obes Surg 2003;13:10-16.

7 Baltasar A, Serra C, Perez N, Bou R, Bengochea M, Ferri L: Laparoscopic sleeve gastrectomy: a multi-purpose bariatric operation. Obes Surg 2005; 15:1124-1128.

$\checkmark 8$ Weiner RA, Weiner S, Pomhoff I, Jacobi C, Makarewicz W, Weigand G: Laparoscopic sleeve gastrectomy - influence of sleeve size and resected gastric volume. Obes Surg 2007;17:1297-1305.

$\checkmark 9$ Hess DS, Hess DW, Oakley RS: The biliopancreatic diversion with the duodenal switch: results beyond 10 years. Obes Surg 2005;15:408-416.

10 Mognol P, Chosidow D, Marmuse JP: Laparoscopic sleeve gastrectomy as an initial bariatric operation for high-risk patients: initial results in 10 patients. Obes Surg 2005;15:1030-1033.

11 Felberbauer FX, Langer F, Shakeri-Manesch S, Schmaldienst E, Kees M, Kriwanek S, Prager M, Prager G: Laparoscopic sleeve gastrectomy as an isolated bariatric procedure: intermediate-term results from a large series in three Austrian centers. Obes Surg 2008;18:814-818.

12 Langer FB, Bohdjalian A, Felberbauer FX, Fleischmann E, Reza Hoda MA, Ludvik B, Zacherl J, Jakesz R, Prager G: Does gastric dilatation limit the success of sleeve gastrectomy as a sole operation for morbid obesity? Obes Surg 2006;16:166171.

13 Almogy G, Crookes PF, Anthone GJ: Longitudinal gastrectomy as a treatment for the high-risk superobese patient. Obes Surg 2004;14:492-497.
14 Nocca D, Krawczykowsky D, Bomans B, Noel P, Picot MC, Blanc PM, de Seguin de HC, Millat B, Gagner M, Monnier L, Fabre JM: A prospective multicenter study of 163 sleeve gastrectomies: results at 1 and 2 years. Obes Surg 2008;18:560-565.

15 Alexander JW, Martin Hawver LR, Goodman HR: Banded sleeve gastrectomy - initial experience. Obes Surg 2009;19:1591-1596.

16 Agrawal S, Van DE, Akin F, Van CS, Dillemans B: Laparoscopic adjustable banded sleeve gastrectomy as a primary procedure for the super-super obese (body mass index $>60 \mathrm{~kg} / \mathrm{m}^{2}$ ). Obes Surg 2010;20:1161-1163.

17 Fobi MA: Placement of the GaBP ring system in the banded gastric bypass operation. Obes Surg 2005;15:1196-1201.

18 Karcz WK, Kuesters S, Marjanovic G, Suesslin D, Kotter E, Thomusch O, Hopt UT, Felmerer G, Langer M, Baumann T: 3D-MSCT gastric pouch volumetry in bariatric surgery-preliminary clinical results. Obes Surg 2009;19:508-516.

19 Hess DS, Hess DW: Biliopancreatic diversion with a duodenal switch. Obes Surg 1998;8:267-282.

20 Marceau P, Biron S, Bourque RA, Potvin M, Hould FS, Simard S: Biliopancreatic diversion with a new type of gastrectomy. Obes Surg 1993;3:29-35.

21 Marceau P, Hould FS, Potvin M, Lebel S, Biron S: Biliopancreatic diversion (duodenal switch procedure). Eur J Gastroenterol Hepatol 1999;11:99-103.

-22 Rabkin RA, Rabkin JM, Metcalf B, Lazo M, Rossi M, Lehmanbecker LB: Laparoscopic technique for performing duodenal switch with gastric reduction. Obes Surg 2003;13:263-268.

23 Ren CJ, Patterson E, Gagner M: Early results of laparoscopic biliopancreatic diversion with duodenal switch: a case series of 40 consecutive patients. Obes Surg 2000;10:514-523.

24 Regan JP, Inabnet WB, Gagner M, Pomp A: Early experience with two-stage laparoscopic Roux-en-Y gastric bypass as an alternative in the super-super obese patient. Obes Surg 2003;13:861-864.

25 Nguyen NT, Longoria M, Gelfand DV, Sabio A, Wilson SE: Staged laparoscopic Roux-en-Y: a novel two-stage bariatric operation as an alternative in the super-obese with massively enlarged liver. Obes Surg 2005;15:1077-1081.

26 Milone L, Strong V, Gagner M: Laparoscopic sleeve gastrectomy is superior to endoscopic intragastric balloon as a first stage procedure for superobese patients $(\mathrm{BMI}>$ or $=50$ ). Obes Surg 2005;15: 612-617.
7 Moon HS, Kim WW, Oh JH: Results of laparoscopic sleeve gastrectomy (LSG) at 1 year in morbidly obese Korean patients. Obes Surg 2005;15: 1469-1475.

28 Himpens J, Dapri G, Cadiere GB: A prospective randomized study between laparoscopic gastric banding and laparoscopic isolated sleeve gastrectomy: results after 1 and 3 years. Obes Surg 2006; 16:1450-1456.

29 Himpens J, Dobbeleir J, Peeters G: Long-term results of laparoscopic sleeve gastrectomy for obesity. Ann Surg 2010;252:319-324.

30 Gagner M, Rogula T: Laparoscopic reoperative sleeve gastrectomy for poor weight loss after biliopancreatic diversion with duodenal switch. Obes Surg 2003;13:649-654.

31 Crampton NA, Izvornikov V, Stubbs RS: Silastic ring gastric bypass: a comparison of two ring sizes: a preliminary report. Obes Surg 1997;7:495-499.

32 Stubbs RS, O'Brien I, Jurikova L: What ring size should be used in association with vertical gastric bypass? Obes Surg 2006;16:1298-1303.

33 Fobi M, Lee H, Igwe D, Felahy B, James E, Stanczyk M, Fobi N: Band erosion: incidence, etiology, management and outcome after banded vertical gastric bypass. Obes Surg 2001;11:699-707.

34 Karcz WK, Suslin D, Baumann T, Utzolino S, Küsters S, Makarewicz WJ, Richter S, TittelbachHelmrich D, Hoeppner J, Thomusch O, Marjanovic G: To have or not to have the ring: early and late surgical complications after banded Rouxen-Y gastric bypass. Videosurgery Minimal Invasive Techniques 2008;3:53-65.

35 Marquez MF, Ayza MF, Lozano RB, Morales MM, Diez JM, Poujoulet RB: Gastric leak after laparoscopic sleeve gastrectomy. Obes Surg 2010;20:13061311.

36 Csendes A, Braghetto I, Leon P, Burgos AM: Management of leaks after laparoscopic sleeve gastrectomy in patients with obesity. J Gastrointest Surg 2010;14:1343-1348.

37 Kelogrigoris M, Sotiropoulou E, Stathopoulos K, Georgiadou V, Philippousis P, Thanos L: CT-guided percutaneous drainage of infected collections due to gastric leak after sleeve gastrectomy for morbid obesity: initial experience. Cardiovasc Intervent Radiol 2010; DOI: 10.1007/s00270-010-9928-5.

38 Nguyen NT, Nguyen XM, Dholakia C: The use of endoscopic stent in management of leaks after

sleeve gastrectomy. Obes Surg 2010;20:1289-1292.
39 Loske G, Schorsch T, Muller C: Endoscopic vacuum sponge therapy for esophageal defects. Surg Endosc 2010;24:2531-2535. 